\title{
Vascular Mechanisms of Cyclosporin-induced Hypertension in the Rat
}

\author{
Jean-Baptiste Roullet, Hong Xue, David A. McCarron, Scott Holcomb, and William M. Bennett
}

Division of Nephrology, Hypertension and Clinical Pharmacology, Oregon Health Sciences University, Portland, Oregon, 97201

\begin{abstract}
Numerous studies have explored the pathogenesis of cyclosporin A (CysA)-induced hypertension; however, none has assessed the impact of CysA treatment on resistance arteries in the setting of elevated blood pressure. Therefore, we studied the chronic effect of CysA on rat mesenteric artery resistance vessels (ex vivo). CysA ( $25 \mathrm{mg} / \mathrm{kg}$ per d for $7 \mathrm{~d}$ ), but not vehicle, significantly raised systolic blood pressure $(13.4 \pm 2.2$ $\mathrm{mmHg}, P<0.003, n=9$ per group). The resistance vessels from CysA-treated rats showed a small but significant decrease in norepinephrine sensitivity $(P<0.03)$ and a pronounced decrease in endothelium-dependent and -independent relaxation $(P<0.001)$ compared to controls. Endothelin-1 sensitivity tended to be diminished $(P=0.07)$. The direct (in vitro) effect of CysA was subsequently evaluated in resistance vessels from nontreated animals $(n=8)$ and exposed to CysA $(2 \mu \mathrm{g} / \mathrm{ml})$ for $24 \mathrm{~h}$. As observed in vivo, CysA significantly decreased endothelium-dependent and -independent relaxations $(P<0.05)$ and attenuated norepinephrine sensitivity $(P=0.06)$. Methylene blue, a nitric oxide quencher, significantly inhibited the acetylcholine-induced relaxation in control, but not in CysA vessels, suggesting a selective action of CysA on the nitric oxide pathway. We conclude that CysA-induced hypertension is the consequence of a primary effect on resistance vessel relaxation, not increased vasoconstriction, as previously suggested. (J. Clin. Invest. 1994. 93:2244-2250.) Key words: cyclosporin A • resistance vessels $\bullet$ ex vivo $\bullet$ blood pressure $\bullet$ in vivo
\end{abstract}

\section{Introduction}

Cyclosporin A (CysA) ${ }^{1}$, a neutral cyclic undecapeptide of fungal origin, is a potent immunosuppressor agent widely used in organ transplantation. Its use has been limited by several side effects including hypertension, nephrotoxicity, and hypercholesterolemia (reviewed in reference 1). CysA-induced hypertension is frequent in solid organ transplantation, as well as

Part of this work was presented at the annual meeting of the American Society of Hypertension, 19-23 May 1993, New York.

Address correspondence and reprint requests to Jean-Baptiste Roullet, Ph.D., Division of Nephrology and Hypertension, L-463, 3181 S. W. Jackson Park Road, Oregon Health Sciences University, Portland, OR 97201.

Received for publication 24 June 1993 and in revised form 4 October 1993.

1. Abbreviations used in this paper: CysA, cyclosporin A; ET-1, endothelin-1; MARV, mesenteric artery resistance vessels; NE, norepinephrine; NO, nitric oxide; SNP, sodium nitroprusside.

J. Clin. Invest.

(c) The American Society for Clinical Investigation, Inc.

0021-9738/94/05/2244/07 \$2.00

Volume 93, May 1994, 2244-2250 autoimmune disease (2). Though renal dysfunction is usually also present, blood pressure elevations have been observed in the absence of detectable renal dysfunction in both animals (3) and humans (4). Numerous studies have been conducted in various animal models to elucidate the vascular changes that might be responsible for the elevation of blood pressure. Most of them have reported a significant impact of the drug on large or medium arteries $(5-10)$ or on whole vascular beds $(11,12)$. Few studies, though, have addressed the impact of the drug on resistance vessels: in vitro studies with human subcutaneous arterioles $(13,14)$ or ex vivo experiments conducted with renal microvessels in the context of CysA nephrotoxicity (15). To date, there are no data available on the reactivity of resistance arteries studied ex vivo after chronic administration of CysA in the presence of drug-induced hypertension. Finally, in many studies in which altered vascular reactivity was demonstrated $(6,7,10,15)$, there was no documented elevation of blood pressure, thereby bringing into question the relevance of the observed vascular changes to hypertension. The objectives of the present study were $(a)$ to evaluate the vascular consequences of the drug treatment at the level of resistance arteries (ex vivo study) in an animal model of cyclosporin A-induced hypertension and $(b)$ to determine if the vascular dysfunctions observed in CysA-treated animals could be the consequences of a direct action of the drug (in vitro study). To accomplish this, a rat model of CysA-induced hypertension was developed in which elevation of blood pressure coexisted with functional alteration of the reactivity of resistance vessels. Similar vascular dysfunction was reproduced after direct and chronic in vitro exposure of the vessels to the drug supporting the hypothesis that CysA-induced vascular toxicity is a cause of drug-induced systemic hypertension.

\section{Methods}

Animals. 12-14-wk old male Sprague Dawley rats (Charles River Laboratories, Wilmington, MA) were used for all experiments. They were fed ad libitum a standard rat chow (Ralston-Purina Co., St. Louis, MO), had free access to water, and were submitted to a 12-h dark-light cycle. All rats were fasted for 16-18 h before death.

Experimental protocols. Two experiments were performed. Experiment 1 examined the changes in the reactivity of resistance vessels associated with the elevation of blood pressure induced by chronic administration of CysA, while experiment 2 was intended to demonstrate that the observed in vivo changes could be reproduced in vitro by direct and long-term exposure of resistance vessels to the drug.

In experiment 1 , the animals $(n=18)$ were randomly assigned to either the CysA group or the control (vehicle) group. CysA rats received daily subcutaneous injections (9:00 a.m.) of cyclosporin A (generously provided by Sandoz Pharmaceuticals Corp., East Hanover, NJ) solubilized in olive oil at the dose of $25 \mathrm{mg} / \mathrm{kg}$ body wt for $7 \mathrm{~d}$. Control rats received olive oil only $(500 \mu \mathrm{l})$. Systolic blood pressure was measured daily by a tail-cuff method (Narco-Bio, Houston, TX) for three consecutive days before the treatment period and during final $3 \mathrm{~d}$ of treatment. On day 8 , the rats were killed by decapitation, and the vascular reactivity of the mesenteric artery resistance vessels was studied. Another group of animals (six control and six CysA-treated rats) was 
subjected to the same injection protocol and used for further characterization of the experimental model. In this group, blood pressure and body weight were monitored daily for 2 wk ( 1 wk of baseline and 1 wk of treatment), and blood analysis was performed on day 8 . None of the control group was pair fed, since we observed that a food restriction comparable to the decreased food intake usually observed in rats treated with CysA did not impact significantly on either systolic blood pressure or vascular reactivity (not shown).

For testing the direct effect of cyclosporin A on the reactivity of resistance vessels (experiment 2 ), nontreated animals were used (same strain, sex, and age as for the in vivo experiments).

Measurement of vascular reactivity. Mesenteric artery resistance vessels (MARV) were isolated and prepared as previously described (16). Briefly, the mesenteric artery bed was excised and rinsed with saline. Resistance vessels from the second branch of the mesenteric artery were studied. For each rat, two vessels were analyzed and their responses were averaged. In experiment 2 (in vitro), four segments ( $\sim 1 \mathrm{~cm}$ long) of MARV were prepared as above and further incubated for $24 \mathrm{~h}$ with either CysA ( $2 \mu \mathrm{g} / \mathrm{ml}$ ) or ethanol (as vehicle, $0.1 \%$, $\mathrm{vol} / \mathrm{vol}$ ) in Dulbecco's modified essential medium supplemented with antibiotics (penicillin and streptomycin) at $37^{\circ} \mathrm{C}$ in a $5 \% \mathrm{CO}_{2}$ atmosphere. Preliminary experiments showed that a 24-h exposure to $0.1 \%$ ethanol had no significant influence on their reactivity (not shown). Vessels were then mounted in a myograph and set at their optimal length for force development by construction of a length-tension curve. The diameter of the vessels and the arterial wall thickness were measured using a filar micrometer eyepiece. The reactivity (contraction or relaxation) to cumulative addition of norepinephrine (NE), endothelin-1 (ET-1), acetylcholine, or sodium nitroprusside (SNP) was measured after an initial equilibration period of $30 \mathrm{~min}$. The acetylcholineinduced relaxation was also tested after a 10 -min incubation with $1 \mu \mathrm{M}$ methylene blue. Responses were reported as absolute force normalized to axial length of the vessel (active tension in millinewton per millimeter) for contractions or percent of precontraction with NE for relaxations ( $100 \%$ equals no relaxation). When appropriate, efficient doses $\left(\mathrm{ED}_{50}\right)$ were calculated.

Blood chemistry. Urea, creatinine, and $\mathrm{Mg}^{2+}$ levels were determined on plasma using standard laboratory techniques.

Statistical analysis. Results are presented as mean \pm SEM. The statistical difference between two groups of independent values was estimated using Student's $t$ test. Paired tests were used when the vessels from the same animal were used to test both CysA and vehicle (experiment 2). Repeated measures analysis of variance and linear regression analysis were used to assess the trends of blood pressure and body weight over time.

\section{Results}

Experiment 1. Chronic administration of CysA significantly increased systolic blood pressure in the animals used for the vascular study, while administration of vehicle did not (Fig. 1, experiment 1 ). The average body weight gain during the treatment period (days 0-8) was significantly reduced in the CysA group by comparison with controls: $10 \pm 18$ and $59 \pm 25 \mathrm{~g}$, respectively $(P<0.001)$. The results were confirmed in a subgroup of rats $(n=6)$ for which the kinetics of the drug action on blood pressure and body weight were better characterized by daily measurements; as shown in Figs. 2 and 3, the elevation of blood pressure and the inhibition of body weight gain started at the time of drug injection. Based on linear regression analysis, the blood pressure slope with respect to time was higher in the CysA than in the control group $(+1.97$ vs. $-0.16 \mathrm{mmHg} /$ $\mathrm{d}, P<0.001$ ), while body weight slopes were 1.3 and $3.5 \mathrm{~g} / \mathrm{d}$, respectively $(P<0.02)$. The plasma level of urea was significantly elevated in CysA rats when compared with controls ( Table I). Creatinine level was not different. Plasma $\mathrm{Mg}^{2+}$ concen-

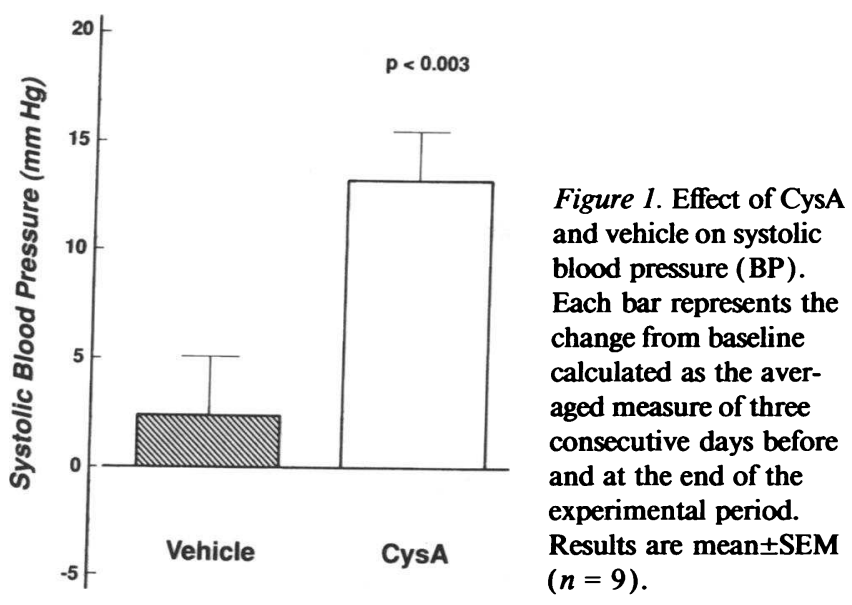

tration was significantly decreased. The resistance vessels from the animals treated with CysA did not show significant alteration of lumen diameter $(290 \pm 11$ vs $283 \pm 13 \mu \mathrm{m})$ or wall thickness $(32.1 \pm 1.1$ vs $32.1 \pm 1.1 \mu \mathrm{m})$ compared to the control vessels. The maximum response (active tension) to ET-1 was similar in both groups (data not shown). However, the $\mathrm{ED}_{50}$ tended to be increased $(P=0.07$, Fig. 4$)$ in vessels isolated from CysAtreated rats, indicating decreased sensitivity to ET-1. The sensitivity to NE, but not the maximum contraction, was significantly decreased in the CysA vessels (Figs. 4 and 5 ). Maximum relaxation and sensitivity to acetylcholine were significantly decreased in CysA-treated rats (Fig. 6). Sensitivity to Na nitroprusside was also decreased (significant shift of the dose-response curve to the right) in CysA-treated rats compared to those receiving the vehicle (Fig. 7). However, the maximum response to $\mathrm{Na}$ nitroprusside was identical in both groups.

Experiment 2. The response to ET-1 was similar in both CysA- and vehicle-incubated resistance vessels (data not shown). As observed in the ex vivo experiment, the NE doseresponse curve was shifted to the right in CysA vessels as compared to controls (Fig. 8), associated with an increase of $E_{50}$ : $297 \pm 52$ vs $210 \pm 21 \mathrm{nM}$ for CysA and vehicle, respectively $(P$ $=0.06, n=8$ ). The maximum relaxation induced by acetylcholine was significantly decreased in the resistance vessels

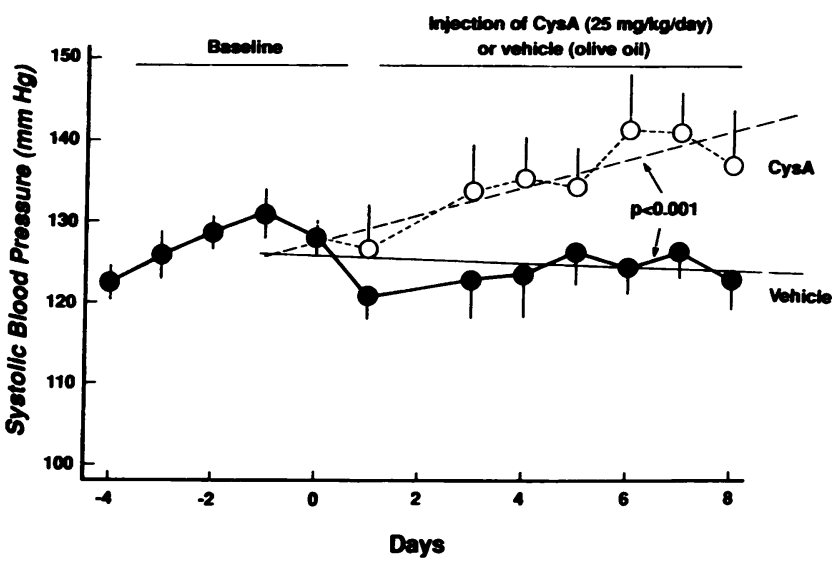

Figure 2. Time-course development of the effect of CysA on systolic $\mathrm{BP}(n=6 /$ group $)$. Slopes were obtained by linear regression analysis of BP vs time (days $0-8$ ). $P<0.05$ indicates a statistically significant difference between the slopes. 


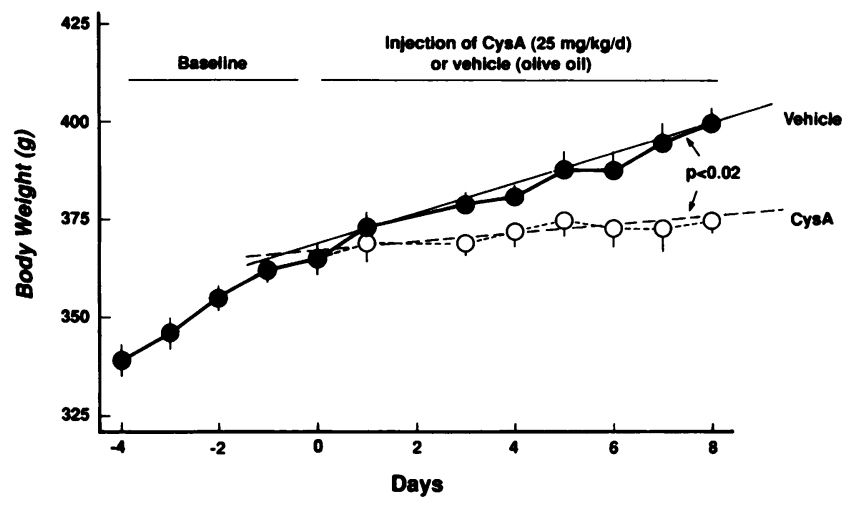

Figure 3. Time-course development of the effect of CysA on body weight ( $n=6 /$ group). Slopes were obtained by linear regression analysis of body weight vs time (days $0-8$ ). $P<0.05$ indicates a statistically significant difference between the slopes.

preincubated with CysA (Fig. 9). This figure also shows that the dose-response curve was shifted to the right of the control curve, indicating a decreased sensitivity to the neuromediator. Preincubation of the vehicle-treated vessels with methylene blue $(1 \mu \mathrm{M})$ for $10 \mathrm{~min}$ before addition of acetylcholine significantly shifted the dose-response curve to the right by comparison with the curve obtained without methylene blue (Fig. 10 $A)$. In contrast, methylene blue had no effect on the response to acetylcholine of CysA-treated vessels (Fig. $10 \mathrm{~B}$ ). Finally, CysA-treated vessels showed decreased sensitivity to $\mathrm{Na}$ nitroprusside as compared to controls (Fig. 11); both preparations relaxed to the same extent when challenged with maximum concentrations of $\mathrm{Na}$ nitroprusside.

\section{Discussion}

The present study was intended to further characterize the vascular impact and mechanisms of cyclosporine $\mathrm{A}$ using a rat model with fixed hypertension. Chronic administration of CysA ( $25 \mathrm{mg} / \mathrm{kg}$ body wt/d solubilized in olive oil) significantly and reproducibly raised systolic blood pressure in our experimental model. After $7 \mathrm{~d}$ of treatment, the average elevation of blood pressure was $\sim 15 \mathrm{mmHg}$. This effect was associated with a significant decrease of body weight gain, with increased plasma urea levels, and with no significant change in plasma creatinine concentrations. Systemic hypertension has been successfully reproduced in animals given the drug either acutely or chronically. However, the data are inconsistent: reports of increase $(8,17,18)$, decrease (19), or absence (20-22) of effect on blood pressure have been published. Differences in strain may account for such variation. Differences in the dose

Table I. Plasma Urea, Creatinine, and $\mathrm{Mg}^{2+}$ Levels in Vehicle- and CysA-treated Animals

\begin{tabular}{llcr}
\hline & Vehicle & CysA & \multicolumn{1}{c}{$P$} \\
\hline Urea $(\mathrm{mM})$ & $5.26 \pm 0.27$ & $10.52 \pm 0.67$ & $<0.001$ \\
Creatinine $(\mu \mathrm{M})$ & $97.0 \pm 4.1$ & $97.1 \pm 4.6$ & $(0.98)$ \\
$\mathrm{Mg}^{2+}(\mathrm{mM})$ & $0.72 \pm 0.01$ & $0.52 \pm 0.01$ & $<0.001$
\end{tabular}

Results are mean $\pm \operatorname{SEM}(n=6$ rats per group).

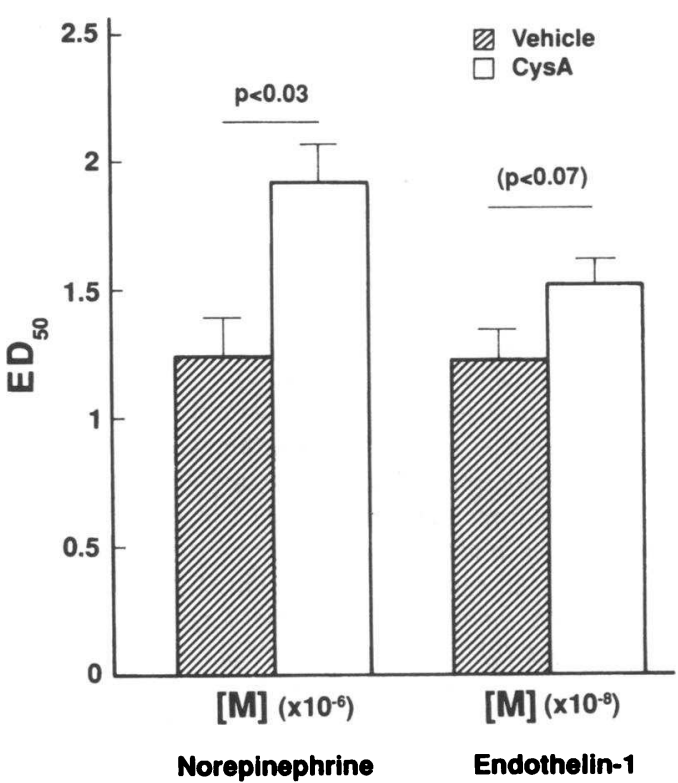

Figure 4. $\mathrm{ED}_{50}$ of MARV to ET-1 and NE. Vessels were isolated from animals ( $n=9$ /group) pretreated with either CysA ( $\square$ ) or vehicle ( $(\square)$.

(ranging from 1 to $60 \mathrm{mg} / \mathrm{kg}$ per d), the duration of treatment, and the type of vehicle (olive oil, olive oil plus ethanol, or Cremophor-EL) are also likely to influence the consistency of the results. We chose a dose of CysA that has been previously reported to increase systemic blood pressure in normotensive rats $(8,23)$. We also decided to study the rats after $7 \mathrm{~d}$ of treatment, a relatively short period of time compared to many other studies $(6,7,9,23)$, to detect the early functional changes of the vasculature that may mediate the elevation of blood pressure. Finally, because of reports suggesting a potential toxicity of the vehicle for parenteral CysA (Cremophor-EL, [24]), we solubilized the drug in olive oil.

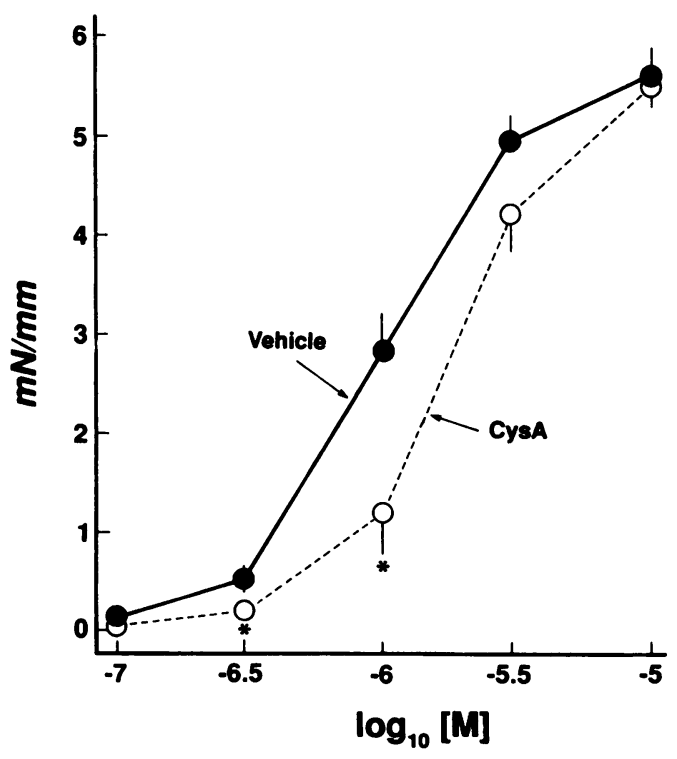

Figure 5. Reactivity of MARV to NE. Vessels were isolated from animals ( $n=9$ /group) pretreated with either CysA (0---0) or vehicle $(\bullet-\bullet)$. *Statistical difference $(P<0.05)$. 


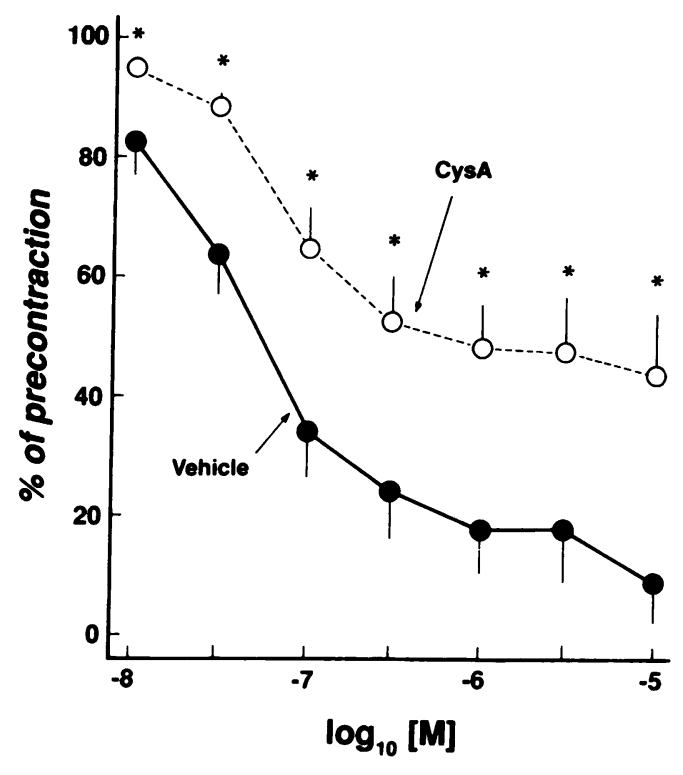

Figure 6. Reactivity of MARV to acetylcholine. Vessels were isolated from animals ( $n=9 /$ group) pretreated with either CysA (0---O) or vehicle $(\bullet-\bullet)$ and precontracted with NE. *Statistical difference $(P<0.05)$.

A significant inhibition of body weight gain was observed in association with the rise in blood pressure. The decreased body weight gain is a previously recognized side effect of CysA administration in humans and animals $(25,26)$, and could be accounted for by a reduction in food intake (not measured in this study) or by a catabolic effect of the drug as suggested by the elevation of plasma urea in CysA animals. Global reduction in food intake is unlikely to play a role in the pathogenesis of CysA-induced hypertension, since chronic underfeeding has been reported to decrease blood pressure (27). However, there

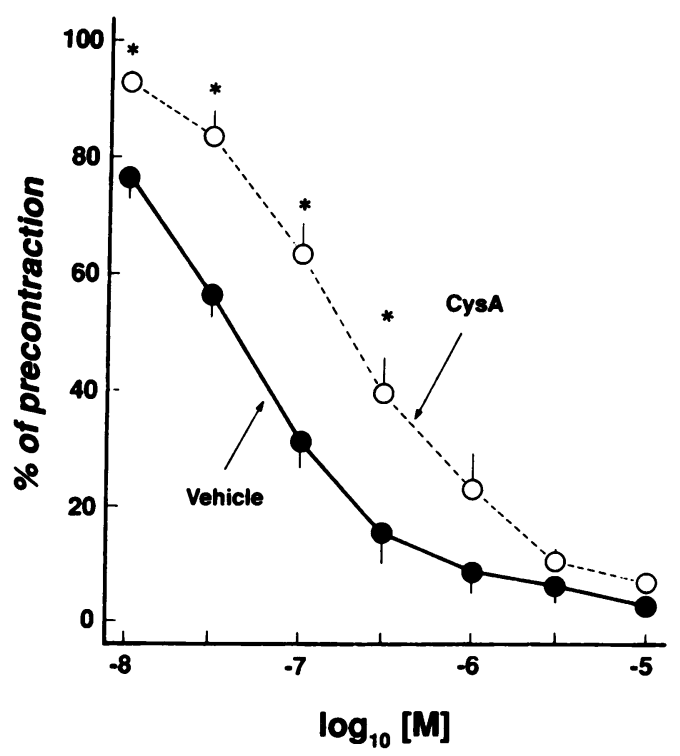

Figure 7. Reactivity of MARV to sodium nitroprusside. Vessels were isolated from animals ( $n=9$ /group) pretreated with either CysA $(0---O)$ or vehicle $(\bullet-\bullet)$ and precontracted with NE. *Statistical difference $(P<0.05)$.

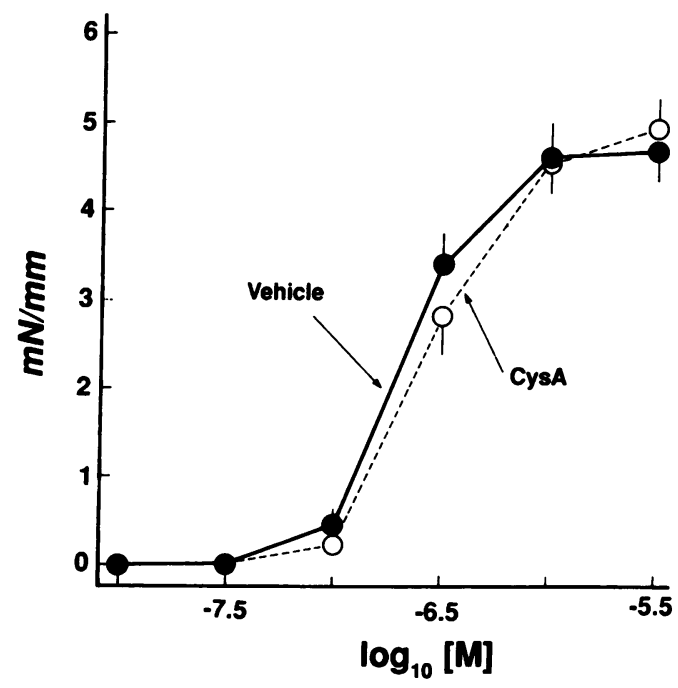

Figure 8 . Reactivity of MARV to NE. Vessels were isolated from nontreated rats $(n=8)$ and incubated with CysA $(0---0)$ or vehicle $(\bullet-\bullet)$ for $24 \mathrm{~h}$ (for conditions, see Methods).

is a possibility that the drug impairs the intestinal absorption of a specific nutrient critical to the control of systemic blood pressure, such as magnesium or calcium, thereby increasing blood pressure.

Drug-induced elevation of blood pressure was associated with significant alterations of the resistance vessel reactivity to pressure hormonal mediators: small but significant decreased sensitivity to NE, profound impairment of endothelium-dependent (acetylcholine) relaxation, and decreased sensitivity to endothelium-independent relaxing factors ( $\mathrm{Na}$ nitroprusside). These effects were reproduced in vitro by chronic (24-h) direct exposure of the vessels to the drug. Our findings offer the first direct evidence of altered reactivity of resistance vessels in the context of CysA-associated hypertension. Impaired reactivity of larger vessels such as aorta (6), smaller arteries such as renal intralobar arteries (6), or mesenteric arterial bed isolated

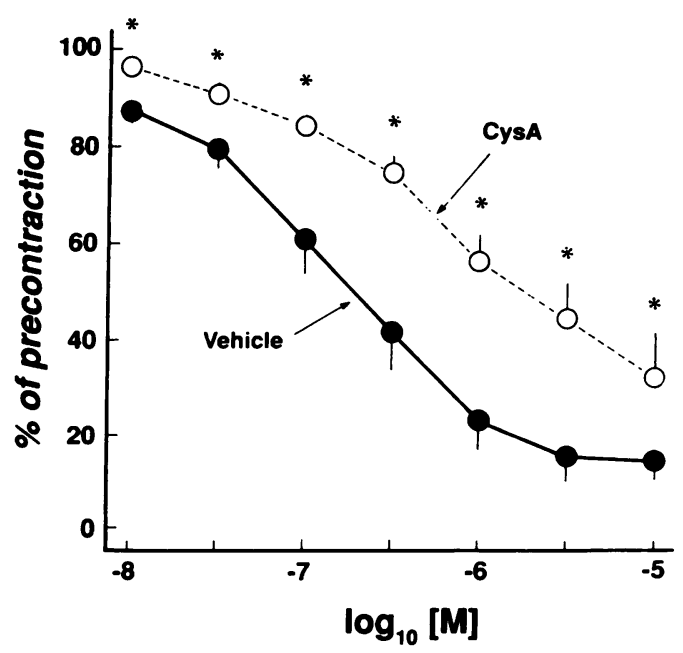

Figure 9. Reactivity of MARV to acetylcholine. Vessels were isolated from nontreated rats $(n=8)$ and incubated with CysA (O---O) or vehicle $(\bullet-\bullet)$ for $24 \mathrm{~h}$ (for conditions, see Methods). *Statistical difference $(P<0.05$, paired $t$ test $)$. 


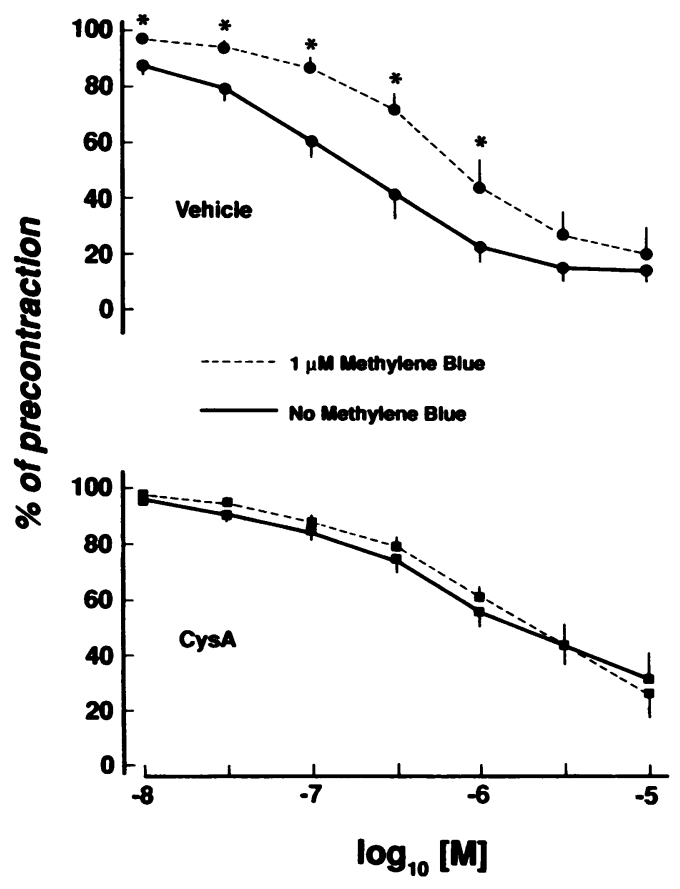

Figure 10. Effect of methylene blue on acetylcholine-induced relaxation of MARV isolated from nontreated rats $(n=8)$ and incubated with vehicle $(A)$ or CysA $(B)$ for $24 \mathrm{~h}$ (for conditions, see Methods). *Statistical difference $(P<0.05$, paired $t$ test $)$.

from animals pretreated with CysA $(8,12)$ has been documented. However, large vessels do not contribute significantly in the maintenance of blood pressure; therefore, the relevance of the findings obtained with nonresistance vessels to the pathogenesis of CysA-induced hypertension remains questionable. Resistance vessels are believed to play a central role in the peripheral control of systemic blood pressure ( reviewed in reference 28). Small changes in their relaxation or contraction prop-

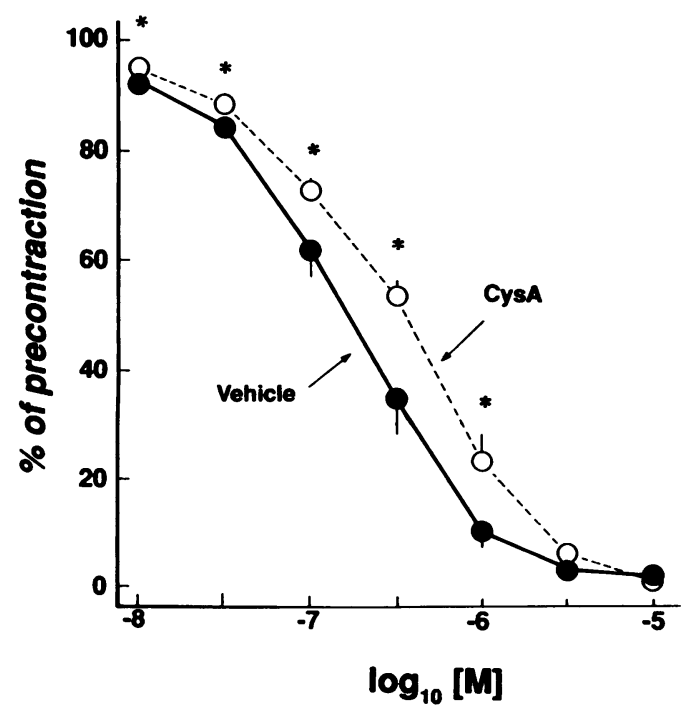

Figure 11. Reactivity of MARV to sodium nitroprusside. Vessels were isolated from nontreated rats $(n=8)$ and incubated with CysA $(0---0)$ or vehicle $(\bullet-\bullet)$ for $24 \mathrm{~h}$ (for conditions, see Methods). *Statistical difference $(P<0.05$, paired $t$ test $)$. erties have a potentially large impact on the resistance to blood flow and, ultimately, on arterial pressure. The role of the observed vascular changes in the pathogenesis of hypertension is questionable, particularly if one considers that the impaired response to vasoconstrictors may offset the predominant effect on vasorelaxation. However, since the impact of the drug on maximal vasorelaxation is profound (Fig. 6), and that on vasoconstriction is limited to a decrease in sensitivity (Figs. 4 and $5)$, we believe that the net effect is a decreased vasodilatory tone, which secondarily sustains the rise in systemic blood pressure.

The decreased sensitivity to NE is in contrast to previous reports of enhanced vascular reactivity to the hormone. Using an isolated rat mesenteric arterial bed preparation that comprised large as well as resistance vessels, Rego et al. (12) showed that chronic administration of CysA induced greater vasoconstrictor response to NE. In a different arterial bed (renal microvessels), Takenaka et al. (15) examined the response to exogenous NE after $5 \mathrm{~d}$ of subcutaneous CysA at $60 \mathrm{mg} / \mathrm{kg}$ per d. At this overtly nephrotoxic dose, afferent and efferent constriction induced by NE was enhanced. Other reports $(6,10)$ obtained with large vessels also documented the increased adrenergic vascular reactivity, further supporting the concept that sympathetic nervous system hyperreactivity was a major pathogenetic factor of CysA-induced hypertension. The current ex vivo and in vitro data do not support this hypothesis. Instead, our findings are in agreement with the conclusions of de Lima et al. (29), that hypersensitivity of resistance vessels to vasoconstriction does not contribute significantly to the development of CysA-induced hypertension. As shown by Mikkelsen et al. (7) and discussed by McNally et al. (30), the effect of CysA may vary according to the type and size of the vessels studied, thus explaining the discrepancy between our results and previous reports. Indeed, not all studies have reported a potentiation of vasoconstriction by NE. At least two in vivo studies $(20,22)$ performed in the rat reported a blunted pressor response with administration of the drug. More interestingly, Richards et al. (14) showed that preincubation of resistance vessels isolated from human fat biopsies with CysA decreased their sensitivity to exogenous NE. The mechanism of the hyposensitivity to NE remains speculative. An excessive stimulation of efferent sympathetic nerve activity by CysA, previously reported by Moss et al. (17) and Xue et al. (5), could have induced the desensitization to NE observed in in vivo studies, as well as in our ex vivo experiment. A recent report from Zanchi et al. (31) showed that chronic in vivo inhibition of NO synthetase with L-arginine analogues was associated with a decreased response of rat mesenteric arterioles to NE. As discussed below, this situation also applies to CysA treatment where a profound impairment of endothelium-dependent vascular relaxation is observed. Therefore, it is also a possibility that the decreased sensitivity to $\mathrm{NE}$ be secondary to a pharmacological effect of the drug on the endothelium. Finally, a direct toxicity of CysA on smooth muscle cells and their contractile components cannot be excluded.

ET-1 is a potent vasoconstrictor produced by endothelial cells (32-34). Its putative role in the pathogenesis of hypertension is supported by several lines of evidence (35-37) suggesting that endothelial damage is generally associated with enhanced release of the vasoconstrictor peptide. An increased number of ET-1 cardiac receptors has been reported in a mouse model given the drug (38). Of greater interest is the recent 
report by Takeda et al. (23) of a stimulated release of ET-1 by the mesenteric artery of Wistar rats chronically treated with 25 $\mathrm{mg} / \mathrm{kg}$ per d CysA. Excessive production may induce a desensitization of the ET-1 receptors, thus explaining the tendency to decreased sensitivity to exogenous ET-1 $(P=0.07$, Fig. 4$)$ observed in our model.

CysA-induced impairment of endothelium-dependent relaxation has been a consistent finding in the literature. Aortic rings either preincubated (11) or isolated from animals pretreated with the drug $(6,7,11)$, human subcutaneous resistance arterioles challenged in vitro by CysA (14), mesenteric vascular beds perfused with CysA (11) and whole animals given CysA (39), all exhibited impaired response to acetylcholine. The renal microvessels of CysA-treated rats also showed a blunted vasodilatory response to acetylcholine (15). A study by Chan et al. (10) was not able to reproduce the effect of CysA on endothelium-dependent relaxation. However, the authors used a much lower dose $(5 \mathrm{mg} / \mathrm{kg}$ per $\mathrm{d}$ for 7 and $21 \mathrm{~d}$ ) than that used in the present study. They also did not characterize the systemic blood pressure of the animals, which is unlikely to be elevated at this dose. An adverse impact of CysA on arterial smooth muscle and endothelium-independent relaxation has not been consistently observed previously. Several in vitro and ex vivo studies using large vessels or mesenteric arterial bed preparations $(6,8,9,11)$ described the blunting effect of CysA on $\mathrm{Na}$ nitroprusside-evoked relaxation. In contrast, other in vitro (43) and ex vivo (14) studies could not reproduce this finding. Paradoxically, Richards et al. (14) found that the response to $\mathrm{Na}$ nitroprusside was enhanced in human resistance vessels coincubated with CysA. Our results in resistance vessels suggest that impaired smooth muscle relaxation is an additional important factor in the pathogenesis of CysA-induced hypertension.

The molecular mechanism of action of the drug has not been explored in our study and remains to be determined. However, several lines of evidence suggest that a likely intracellular target is the NO metabolic pathway, including the nitric oxide (NO) generation system by the endothelium and the NO effector system in smooth muscle cells. As reported initially by Solagni et al. (40) in spontaneously hypertensive rats, and more recently by Gallego et al. (39) in normotensive animals, the administration of $\mathrm{L}$-arginine prevents the development of CysA-induced hypertension. Since L-arginine is the metabolic substrate of endothelial NO synthetase, the enzyme stimulated by acetylcholine in our vascular studies, these reports suggest that CysA can decrease the generation of NO-dependent endothelium-derived relaxing factors (41). Our observation that methylene blue, a superoxide donor that inactivates endothelium-derived relaxing factors (42), has no effect on the acetylcholine-induced vasodilatation of resistance vessels preincubated with CysA is consistent with the above noted reports and further suggests that the NO generating system is impaired by CysA. The smooth muscle NO effector system, tested with SNP in our study, is also altered by CysA, though to a lesser degree. A previous study by Rego et al. (11) showing decreased guanosine cGMP content in the aorta of rats treated with CysA and decreased cGMP production by large vessels challenged in vitro by the drug suggests that CysA might impair endotheliumindependent relaxation of the resistance vessels by interference with the cGMP pathway.

The existence of a distinctive impact of CysA on endothelium-dependent and -independent relaxations is debatable in our study because the response to acetylcholine depends on both the endothelium and the smooth muscle, and it tests both the NO-generating and effector systems. One might argue that if CysA-treated vessels have diminished ability to relax, whether to NO-dependent or -independent stimuli, then they will certainly be less affected when NO synthesis is inhibited (e.g., by methylene blue), thus pointing to impaired smooth muscle function as the sole expression of CysA vascular toxicity. We do not believe this is the case based on examination of the dose-response curves to both acetylcholine and SNP in the ex vivo experiments. Fig. 6 shows that maximal doses of acetylcholine cannot relax CysA-treated vessels to the same extent as controls. On the contrary, full relaxation can be achieved with maximal doses of SNP (Fig. 7) despite a diminished sensitivity. This strongly suggests that CysA impacts on the endothelium and the smooth muscle differently.

In conclusion, our study provides direct experimental evidence of the in vivo vascular toxicity of cyclosporin A. The adverse impact of the drug was demonstrated in resistance vessels in the setting of sustained hypertension and was characterized essentially by a decreased response to endothelium-dependent and -independent relaxation pathways. Our data strongly suggest that an initial decrease of vasodilatory tone, and not hyperreactivity to vasoconstrictors, is responsible for elevation of systemic blood pressure observed in the animals receiving CysA. The in vivo effects of the drug on resistance arteries were reproduced in vitro, further supporting the hypothesis of a direct action of the drug on the endothelium and vascular smooth muscle of resistance vessels. Additional studies are needed to determine the specific impact of CysA on the nitric oxide pathway.

\section{Acknowledgments}

We thank Thongchanh Phanouvong and Kate Nilan for their excellent technical assistance.

This work was supported by Research Grant NIDDK Clinical Nutrition Research Unit P30 DK40566-04 from the National Institutes of Health.

\section{References}

1. Kahan, B. D. 1989. Cyclosporine. N. Engl. J. Med. 321:1725-1738.

2. Bellet, M., C. Cabrol, P. Sassano, P. Leger, P. Corvol, and J. Menard. 1985. Systemic hypertension after cardiac transplantation: effect of cyclosporine on the renin-angiotensin system. Am. J. Cardiol. 56:927-931.

3. Chapman, J. R., R. Marcen, M. Arias, A. E. G. Raine, M. S. Dunnill, and P. J. Morris. 1987. Hypertension after cardiac transplantation: a comparison of cyclosporine and conventional immunosuppression. Transplantation (Baltimore). 43:860-864.

4. Whitworth, J. A., E. H. Mills, and J. P. Coghlan. 1987. The haemodynamic effects of cyclosporin A in sheep. Clin. Exp. Pharmacol. Physiol. 14:573-580.

5. Xue, H., R. D. Bukoski, D. A. McCarron, and W. Bennett. 1987. Induction of contraction in isolated rat aorta by cyclosporine. Transplantation (Baltimore). 43:715-718.

6. Rego, A., R. Vargas, M. L. Foegh, and P. W. Ramwell. 1988. Effect of cyclosporine A treatment on vascular reactivity of the rat thoracic aorta. Transplant. Proc. 20:572-577.

7. Mikkelsen, E. O., S. H. Poulsen, N. C. B. Nyborg, N. Korsgaard, and J. Sehested. 1992. Difference between aortic and renal vascular reactivity in cyclosporin A treated rats and the effect of cicletanine. Arch. Pharmacol. 345:356-361.

8. Rego, A., R. Vargas, S. Cathapermal, M. Kuwahara, M. L. Foegh, and P. W. Ramwell. 1991. Systemic vascular effects of cyclosporin A treatment in normotensive rats. J. Pharmacol. Exp. Ther. 259:905-915.

9. Huang, H. C., A. Rego, R. Vargas, M. L. Foegh, and P. W. Ramwell. 1987. Nitroprusside-induced vascular relaxation is attenuated in organ-transplanted animals treated with cyclosporine. Transplant. Proc. 19:126-130. 
10. Chan, B. B. K., J. A. Kern, T. L. Flanagan, I. L. Kron, and C. G. Tribble. 1992. Effects of in vivo cyclosporine administration on endothelium-dependent responses in isolated vascular rings. Circulation. 86:SII-295-SII-299.

11. Rego, A., R. Vargas, B. Wroblewska, M. L. Foegh, and P. W. Ramwell. 1990. Attenuation of vascular relaxation and cyclic GMP responses by cyclosporin A. J. Pharmacol. Exp. Ther. 252:165-170.

12. Rego, A., R. Vargas, K. R. Suarez, M. L. Foegh, and P. W. Ramwell. 1990. Mechanism of cyclosporin potentiation of vasoconstriction of the isolated rat mesenteric arterial bed: role of extracellular calcium. J. Pharmacol. Exp. Ther. 254:799-808.

13. Richards, N. T., L. Poston, and P. J. Hilton. 1990. Cyclosporin A inhibits endothelium-dependent, prostanoid-induced relaxation in human subcutaneous resistance vessels. J. Hypertens. 8:159-163.

14. Richards, N. T., L. Poston, and P. J. Hilton. 1989. Cyclosporine A inhibits relaxation but does not induce vasoconstriction in human subcutaneous resistance vessels. J. Hypertens. 7:1-3.

15. Takenaka, T., Y. Hashimoto, and M. Epstein. 1992. Diminished acetylcholine-induced vasodilation in renal microvessels of cyclosporine-treated rats. $J$. Am. Soc. Nephrol. 3:42-50.

16. Bukoski, R. D., and H. Xue. 1993. On the vascular inotropic action of 1,25-(OH $)_{2}$ vitamin $\mathrm{D}_{3}$. Am. J. Hypertens. 6:388-389.

17. Moss, N. G., S. L. Powell, and R. J. Falk. 1985. Intravenous cyclosporine activates afferent and efferent renal nerves and causes sodium retention in innervated kidneys in rats. Proc. Natl. Acad. Sci. USA. 82:8222-8226.

18. Gerkens, J. F. 1989. Cyclosporine treatment of normal rats produces a rise in blood pressure and decreased renal vascular responses to nerve stimulation, vasoconstrictors and endothelium-dependent dilators. J. Pharmacol. Exp. Ther. 250:1105-1112.

19. Murray, B. M., M. S. Paller, and T. F. Ferris. 1985. Effect of cyclosporine administration on renal hemodynamics in conscious rats. Kidney Int. 28:767774.

20. Garr, M. D. and M. S. Paller. 1990. Cyclosporine augments renal but not systemic vascular reactivity. Am. J. Physiol. 258:F211-F217.

21. Kaskel, F., P. Devarajan, L. A. Arbeit, J. S. Partin, and L. C. Moore. 1987. Cyclosporin nephrotoxicity: sodium excretion, autoregulation and angiotensin II. Am. J. Physiol. 252:F733-F742.

22. Textor, S. C., L. Smith-Powell, and T. Telles. 1990. Altered pressor responses to norepinephrine and ANG II during cyclosporin A administration to conscious rats. Am. J. Physiol. 258:H854-H860.

23. Takeda, Y., I. Miyamori, T. Yoneda, and R. Takeda. 1992. Endothelin-1 release from the mesenteric arteries of cyclosporine-treated rats. Eur. J. Pharmacol. 213:445-447.

24. Yaris, E., M. Tuner, and M. Ilhan. 1992. Actions of cyclosporin A preparation and Cremophor-IL in rabbit mesenteric artery and thoracic aorta in vitro. Clin. Sci. 83:179-182.

25. McCauley, F. T., P. H. Whitting, A. W. Thomson, and J. G. Simpson. 1987. The influence of enalapril or spironolactone on experimental cyclosporine nephrotoxicity. Biochem. Pharmacol. 36:699-703.

26. Gerkens, J. F., S. B. Bhagwandeen, P. J. Dosen, and A. J. Smith. 1984. The effect of salt intake on cyclosporine-induced impairment of renal function in rats. Transplantation (Baltimore). 84:412-417.
27. Natelson, B. H., J. E. Ottenweller, R. J. Servatius, S. Drastal, M. T. Bergen, and W. N. Tapp. 1992. Effect of stress and food restriction on blood pressure and lifespan of Dahl salt-sensitive rats. J. Hypertens. 10:1457-1462.

28. Boudier, H. A. J. S., J. L. M. L. Lenoble, M. W. J. Messing, M. S. P. Huijberts, F. A. C. Lenoble, and H. Vanessen. 1992. The Microcirculation and Hypertension. J. Hypertens. 10:S147-S156.

29. de Lima, J. J. G., W. M. Bennett, J. P. Coghlan, J. G. McDougall, J. J. Tresham, J. A. Whitworth, and B. A. Scoggins. 1988. Cyclosporin A and pressor responsiveness in sheep. J. Cardiovasc. Pharmacol. 11:676-681.

30. McNally, P. G., and J. Feehally. 1992. Pathophysiology of cyclosporin A nephrotoxicity: experimental and clinical observations. Nephrol. Dialysis Transplant. 7:791-804.

31. Zanchi, A., H. R. Brunner, and B. Waeber. 1993. Decreased arterial contractile response to norepinephrine after chronic NO synthetase inhibition in rats Am. J. Hypertens. 6:85A. (Abstr.)

32. Yanagisawa, M., H. Kurihara, S. Kimura, Y. Tomobe, M. Kobayashi, Y. Mitsui, Y. Yazaki, K. Goto, and T. Masaki. 1988. A novel potent vasoconstrictor peptide produced by vascular endothelial cells. Nature (Lond.). 332:411-415.

33. Masaki, T., S. Kimura, M. Yanagisawa, and K. Goto. 1991. Molecular and cellular mechanisms of endothelin regulation. Circulation. 84:1457-1468.

34. Lovenberg, W., and R. C. Miller. 1990. Endothelin: a review of its effects and possible mechanisms of action. Neurochem. Res. 15:407-417.

35. Miyamori, I., Y. Takeda, T. Yoneda, and R. Takeda. 1991. Endothelin release from the mesenteric arteries in spontaneously hypertensive rats. J. Cardiovasc. Pharmacol. 17:S408-S410.

36. Lüscher, T. F., Z. Yang, D. Diederich, and F. R. Bühler. 1989. Endothelium-derived vasoactive substances: potential role in hypertension, atherosclerosis, and vascular occlusion. J. Cardiovasc. Pharmacol. 14:S63-S69.

37. Kon, V., M. Sugiura, T. Inagami, B. R. Harvie, I. Ichikawa, and R. L. Hoover. 1990. Role of endothelin in cyclosporine-induced glomerular dysfunction. Kidney Int. 37:1487-1491.

38. Nayler, W. G., X. H. Gu, D. J. Casley, S. Panagiotopoulos, J. Liu, and P. L. Mottram. 1989. Cyclosporine increases endothelin-1 binding site density in cardiac cell membranes. Biochem. Biophys. Res. Commun. 163:1270-1274.

39. Gallego, M. J., A. L. Farre, A. Riesco, M. Monton, S. M. Grandes, A. Barat, L. Hernando, S. Casado, and C. A. Caramelo. 1993. Blockade of endothelium-dependent responses in conscious rats by cyclosporin A: effect of $L$-arginine Am. J. Physiol. 264:H708-H714.

40. Solagni, K., P. Martasek, M. Schwartzman, L. Korczek, A. Goodman, N. Abraham, and R. D. Levere. 1990. L-arginine protects cyclosporin A-induced blood pressure elevation in spontaneously hypertensive rats. Clin. Res. 38:349.

41. Furchgott, R. F., and J. V. Zawadzki. 1980. The obligatory role of endothelial cells in the relaxation of arterial smooth muscle by acetylcholine. Nature (Lond.). 288:373-376.

42. Marczin, N., U. S. Ryan, and J. D. Catravas. 1992. Methylene blue inhibits nitrovasodilator- and endothelium-derived relaxing factor-induced cyclic GMP accumulation in cultured pulmonary arterial smooth muscle cells via generation of superoxide anion. J. Pharmacol. Exp. Ther. 263:170-179.

43. O'Neil, G. S., A. H. Chester, S. Kushwaha, M. Rose, S. Tadjkarimi, and M. H. Yacoub. 1991. Cyclosporin treatment does not impair the release of nitric oxide in human coronary arteries. Br. Heart J. 66:212-216. 